\title{
Triptans in the Italian population: a drug utilization study and a literature review
}

\author{
Alessandro Panconesi - Eleonora Pavone • \\ Franca Vacca $\cdot$ Monica Vaiani $\cdot$ Roberto Banfi
}

Received: 19 December 2007 / Accepted: 30 January 2008/Published online: 4 March 2008

(C) Springer-Verlag 2008

\begin{abstract}
Previous studies performed in selected populations show a poor utilization of triptans for migraine. The objectives of our study were to establish patterns of triptans utilization in a large sample, covering 1/10 of Italian population (5.57 millions), and to perform a review of published studies on this topic. We investigated drug prescription database collected during 2006 from 33 health authorities distributed in 8 different regions. About $0.6 \%$ of the subjects received at least one prescription of triptans in 1 year: $77.7 \%$ were females and $22.3 \%$ males. Age distribution shows that $9.5 \%$ of patients were aged above 65 , and received prescriptions for $8.2 \%$ of packages. The review of the literature suggests that these percentages of utilization are common to several countries, and shows that occasional triptan users who received only one prescription in 1 year are a large percentage (40-60\%); moreover, a minor population of triptan users utilize a large amount of total triptans. Finally triptans are frequently prescribed in people aged above 65 years, a population in which triptans are contraindicated or not recommended. Our study and the analyzed ones indicate suboptimal treatment of migraine patients with triptans and also an incorrect use in some patients (triptan abusers, elderly).
\end{abstract}

Keywords Triptans - Triptan abusers - Usage patterns · Prescription data $\cdot$ Literature review

\section{Introduction}

Since the commercialization of the new antimigraine drug sumatriptan about 20 years ago, scientific societies,

A. Panconesi · E. Pavone ( $)$ · F. Vacca $\cdot$ M. Vaiani · R. Banfi Florence, Italy

e-mail: e.pavone@us111.toscana.it pharmaceutical companies and headache specialists, have tried to highlight the migraine pathology in the population, arguing that it was underestimated. In the following years many other drugs, in the pharmacological class of triptans, became available.

The average percentage of migraine in the world is regarded as around 9\% of the overall population [1]. However, until today, migraine remains under-diagnosed and under-treated in at least $50 \%$ of patients, and less than $50 \%$ of migraine patients had consulted a physician $[1,2]$. The efficacy of triptans has been shown in several randomized, double-blind, placebo-controlled trials [3]. However these studies were carried out in selected populations and under controlled conditions. Utilization patterns of specific anti-migraine drugs in community patients and the experiences of patients with these drugs in real life setting have been studied less extensively. Recently we have performed a study evaluating triptans utilization in a health authority in Tuscany covering about 225,000 residents $[4,5]$. We have extended this study to establish the patterns of use of triptans in a large sample of Italian population [6] and review other studies on this topic.

\section{Materials and methods}

Study on the Italian population

In the reimbursement system of the Italian National Health Service, all prescribed drugs included within the essential level of assistance (LEA) are recorded by regional health authorities in association with the demographic characteristics of patients. Therefore, medication records of individual patients are quite complete in drugs prescription databases. This allows for accurate investigations in drug 
Table 1 Dosage units contained in triptans packages available in Italy in 2005-2006

\begin{tabular}{lll}
\hline Triptans & Packages & Dosage units \\
\hline Sumatriptan & Tablet 50-100 mg & 4 \\
Sumatriptan & Suppository $25 \mathrm{mg}$ & 2 \\
Sumatriptan & Nasal spray $10-20 \mathrm{mg}$ & 2 \\
Sumatriptan & Injection $6 \mathrm{mg}$ & 2 \\
Zolmitriptan & Tablet $2.5 \mathrm{mg}$ & 3 \\
Zolmitriptan & Soluble tablet $2.5 \mathrm{mg}$ & 2 \\
Rizatriptan & Tablet 5-10 mg & 3 \\
Rizatriptan & Soluble tablet $10 \mathrm{mg}$ & 3 \\
Eletriptan & Tablet $20-40 \mathrm{mg}$ & 3 \\
Almotriptan & Tablet $12.5 \mathrm{mg}$ & 3 \\
Flovatriptan & Tablet $2.5 \mathrm{mg}$ & 2 \\
Flovatriptan & Tablet $2.5 \mathrm{mg}$ & 6 \\
\hline
\end{tabular}

utilization in our setting. The patterns of triptans prescription in the 33 health authorities distributed in 8 Italian regions were investigated. The population studied was 5.57 millions inhabitants, that represents $9.5 \%$ of the Italian population. We analysed prescription database using the ATC classification (Anatomical Therapeutic Chemical classification) NO2CC: triptans, dispensed during 1 year (2006).

In Italy each prescription of triptans could contain one or two packages. In 2006, all triptans (except naratriptan) were available as oral tablets in Italy, for rizatriptan and zolmitriptan as soluble oral tablets, sumatriptan as subcutaneous injections, nasal spray and rectal suppositories. The doses contained in each package of triptans available in Italy are reported in Table 1.

\section{Literature review}

Studies were identified through a Medline search on Internet (Pubmed Medline, 2000 version; address http://www4.ncbi.nlm.nih.gov/PubMed/). This search covered the period from 1991 to June 2007.

\section{Results}

Study on the Italian population

Demographic characteristics of the population studied are reported in Table 2.

On a total of 5,549,731 resident population, the subjects that received triptans were 32,584 ( $0.6 \%$ of the population), $22.3 \%$ males and $77.7 \%$ females. Males and females aged 15-44 represented $51.4 \%$ of total users, while those aged 45-65 were $38.7 \%$. The patients aged over 65 years were
Table 2 Demographic characteristics of the population studied

\begin{tabular}{lrrr}
\hline Age & \multicolumn{1}{l}{ Males } & \multicolumn{1}{c}{ Females } & \multicolumn{1}{c}{ Total } \\
\hline $0-14$ & 370,058 & 348,222 & 718,280 \\
$15-44$ & $1,141,606$ & $1,108,199$ & $2,249,805$ \\
$45-64$ & 697,013 & 722,045 & $1,419,058$ \\
$65-74$ & 280,037 & 329,408 & 609,445 \\
$75-84$ & 169,295 & 258,847 & 428,142 \\
$>85$ & 38,358 & 86,643 & 125,001 \\
Total & $2,696,367$ & $2,853,364$ & $5,549,731$ \\
\hline
\end{tabular}

Table 3 Pattern of triptans utilization in a sample of 5,549,731 Italian residents

\begin{tabular}{llll}
\hline Age & Users (\%) & Packages (\%) & $\begin{array}{l}\text { DDD/1,000 } \\
\text { inhabitants/day }\end{array}$ \\
\hline $0-14$ & 0.2 & 0.08 & 0.004 \\
$15-44$ & 51.4 & 46.1 & 0.813 \\
$45-64$ & 38.7 & 45.5 & 1.324 \\
$65-74$ & 6.2 & 5.9 & 0.446 \\
$75-84$ & 2.7 & 1.9 & 0.216 \\
$>85$ & 0.6 & 0.3 & 0.122 \\
Total (no.) & 32,584 & 312,337 & \\
\hline
\end{tabular}

$D D D$ defined daily dose

9.5\%. The total number of triptan packages prescribed was 312,337 (Table 3). We found the higher dosage (DDD/ 1,000 inhabitants/day, DDD = defined daily dose) in the 45-64 years group. The DDD/1,000 inhabitants/day was: 0.004 (0-14 years), $0.813 \quad(15-44$ years $), 1.324 \quad(45-$ 64 years), 0.446 (65-74 years), 0.216 (75-84 years), 0.122 ( $>85$ years).

The distribution of triptan packages prescribed was: rizatriptan 26\%, sumatriptan $20.1 \%$, almotriptan $17.3 \%$, zolmitriptan $13.9 \%$, eletriptan $12.6 \%$, frovatriptan $10 \%$.

\section{Literature review}

Prevalence of triptan users

A prescription register survey in Denmark revealed that nearly $1 \%$ of the population recurred to sumatriptan in 1year period [7]. Other studies describing the percentage of triptan users, in periods when more triptans are available, are reported in Table 4 [5, 6, 8-15]. The prevalence of triptan users in a year period was $0.55-1.4 \%$. Some of these studies $[8,12,13]$ were performed on new users of triptans who were defined as patients who had not received any triptan in the period preceding the study. The new users account for $25-63 \%$ of total users, depending on the period 
Table 4 Prevalence of triptans users in population studies

\begin{tabular}{|c|c|c|c|c|c|c|}
\hline Study & Country/Year & Population & Users & Period & Percentage & Females $(\%)$ \\
\hline Etemad $^{\mathrm{c}}[8]$ & USA $1998-2000$ & $>2,000,000$ & 8,488 & 1 year & $<0.42$ & 83.6 \\
\hline Lohman $^{\mathrm{a}}$ [9] & Netherlands 2001-2002 & 168,000 & 2,343 & 1 year & 1.4 & 78 \\
\hline Perearnau [10] & France 2003-2004 & $1,793,000$ & 20,686 & 1 year & 1.15 & 78.5 \\
\hline Pavone [5] & Italy 2005 & 224,065 & 1,238 & 1 year & 0.55 & 77.9 \\
\hline Dekker [11] & Netherlands 2005 & $6,700,000$ & 85,172 & 1 year & 1.27 & NR \\
\hline Panconesi [6] & Italy 2006 & $5,549,731$ & 32,584 & 1 year & 0.6 & 77.7 \\
\hline Ifergane $^{c}[12]$ & Israel 2003-2004 & 500,000 & 1,498 & 1 year & 0.3 & 77.1 \\
\hline Lugardon $^{c}[13]$ & France 2002 & $1,550,000$ & 13,860 & 6 months & 1.0 & 80.6 \\
\hline Sondergaard [14] & Denmark 2000 & 472,000 & 2,463 & 3 months & 0.52 & 82.7 \\
\hline Hoffman $^{\mathrm{b}}[15]$ & USA 1999 & 600,000 & 4,718 & 3 months & 0.78 & NR \\
\hline
\end{tabular}

$N R$ not reported

a enclosed also ergotamine, ${ }^{b}$ enclosed also dihydroergotamine nasal spray, ${ }^{c}$ new users

Table 5 Percentage of new users of triptans

\begin{tabular}{lllrrrr}
\hline Study & Antecedent period & Study period & Population & Total users & New users & New users (\%) \\
\hline Lugardon $^{\mathrm{a}}$ (France 2002) [13] & 6 months & 6 months & $1,550,000$ & 13,860 & 8,625 & 63 \\
Sondergaard (Denmark 2000) [14] & 9 months & 3 months & 472,000 & 2,463 & 617 & 25 \\
Etemad (USA 1988) [8] & 6 months & 1 year & $2,000,000$ & 8,488 & 5,383 & 63 \\
\hline
\end{tabular}

${ }^{a}$ among new users, half were occasional users, with only a single prescription during 1 year period

of study and the period considered without assumption preceding the study (Table 5).

The prevalence of triptans utilization in migraine patients in different countries was reported to be 3-19\% (average 10\%) [1], while other population studies show a similar prevalence: $7.5 \%$ [16], $8 \%$ [17], 9.8\% [18]. Therefore the percentage of triptan utilization in the population has a good relation to the pathology, showing that less than $10 \%$ of patients use a triptan.

Migraine patient referred to headache clinics, increase the rate of triptans assumption after consultation [19, 20].

Frequency of triptan use

About $40-60 \%$ of triptans users received only one prescription in 1 year (Fig. 1). Single users of sumatriptan were also reported to be over $40 \%$ [21, 22].

Lohman et al. [9] report that $12.5 \%$ of triptan users utilized more than one drug product and received $25 \%$ of the total number of dosage units. Ifergane et al. [12] report that, among patients who filled more than one prescription, $14.3 \%$ tried a second triptan; in this group $52.1 \%$ purchased only one prescription of the new triptan. Tepper et al. [23] showed that $91 \%$ of the patients remained on the same triptan during the study period. In conclusion 10$15 \%$ of triptans users change the type of triptan during the period of 1 year.

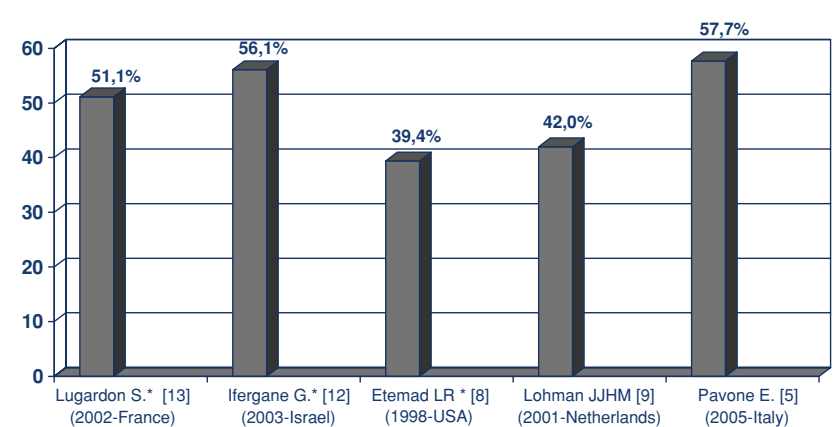

Fig. 1 Percentage of patients receiving only one triptan prescription during 1 year. * New users

On the other hand, a minority of triptan users utilize a large percentage of annual triptan prescriptions (Table 6). A population study in Denmark too showed that a minority of sumatriptan users $(5 \%)$ were taking this medication on a daily basis accounting for $38 \%$ of all sumatriptan use [7].

A comparison of intensity of triptan utilization in different countries cannot be performed considering the number of triptan packages, because triptan packages may contain different number of doses depending on marketing policies. Then a comparison of studies must be performed considering doses or DDD (Table 7).

Initial studies on triptan abuse concerned sumatriptan [7, 24]. The critical intake frequency for patients with triptan 
Table 6 Few patients $(\%)$ of total triptan users consume a large percentage of the triptans prescribed in a year

\begin{tabular}{lll}
\hline Study & $\begin{array}{l}\text { Patients } \\
(\%)\end{array}$ & Consumption (\%) \\
\hline $\begin{array}{l}\text { Perearnau (France 2003) } \\
\quad[10]\end{array}$ & 7.9 & 43.6 of intakes \\
$\begin{array}{l}\text { Dekker (Netherlands 2005) } \\
\quad[11]\end{array}$ & 10.4 & 46 of cost \\
Pavone (Italy 2005) [5] & 5.7 & $\begin{array}{c}40 \text { of packages or } 44 \text { of } \\
\text { DDDs }\end{array}$ \\
\hline
\end{tabular}

$D D D$ defined daily dose

Table 7 Month frequency of triptan assumption

\begin{tabular}{lll}
\hline Pavone (2005 Italy) [5] & 1.8 & DDDs (mean) \\
Perearnau (2003 France) [10] & 2.1 & Doses (mean) \\
Sondergaard (2000 Denmark) [14] & $2.7-3.3$ & Doses (median) \\
Lohman (2001 Netherlands) [9] & 2.9 & Doses (mean) \\
Tepper (2002 USA) [23] & $4.2 \hat{-}-4.6+$ & Doses (mean) \\
\hline
\end{tabular}

$D D D$ defined daily dose

Table 8 Percentage of probable triptans abusers among triptan users

\begin{tabular}{llr}
\hline Study & Criteria & $\%$ \\
\hline Sondergaard (Denmark 2000) [14] & $>15 \mathrm{DDD} / \mathrm{m}$ & 4.7 \\
Lugardon (France 2002) [13] & $15-29 \mathrm{DDD} / \mathrm{m}$ & 10.0 \\
& $>29 \mathrm{DDD} / \mathrm{m}$ & 1.9 \\
Lohman (Netherlands 2001) [9] & $>120 \mathrm{DDD} / \mathrm{y}$ & 5.0 \\
& $>216 \mathrm{DDD} / \mathrm{y}$ & 1.9 \\
Dekker (Netherlands 2005) [11] & $>120 \mathrm{DDD} / \mathrm{y}$ & 10.4 \\
& $>216 \mathrm{DDD} / \mathrm{y}$ & 3.3 \\
Pavone (Italy 2005) [5] & $>120 \mathrm{DDD} / \mathrm{y}$ & 3.2 \\
& $>216 \mathrm{DDD} / \mathrm{y}$ & 0.9 \\
Perearnau (France 2003) [10] & $>144 \mathrm{DDD} / \mathrm{y}$ & 1.9 \\
\hline
\end{tabular}

$D D D$ defined daily dose, $m$ month, $y$ year

overuse headache, is reported to be 18 single doses of triptans per month [25]. Then, considering 216 tablets/year as critical doses for triptan overuse, the percentage of patients overusing triptans are $0.9-3.3 \%$ of all triptans users (Table 8). However, ten single dosages per month (120 doses/year) may be sufficient to cause triptans overuse headache and therefore should be considered a critical threshold $[25,26]$. Therefore, in various studies 3.2-11.9 of patients are possible triptan abusers (Table 8). We cannot classify these patients as suffering of triptan-overuse headache, that is with code 8.2.2 of the International Headache Society (IHS) classification [26], because we do not know their clinical characteristics (headache present on $>15$ day/month, with frequency increased during triptan overuse and impaired within 2 months after triptan discontinuation) and the number of days of triptans intake. However, these patients are probably at risk for developing triptans-overuse headache or rather they already developed this chronic headache.

A consistent percentage of triptans is prescribed for people over the age of 65 . In the Italian population this percentage is $7.6-9.5 \%[5,6]$, higher than that reported $(3.2-3.5 \%)$ in the France population [10, 27]. A previous study shows that sumatriptan users over 65 years were $3 \%$ [28]. This is a population at major risk of hypertension and cardiovascular diseases, and it is also a population in which clinical trials have been not performed and so triptans are not recommended.

\section{Discussion}

The main conclusions coming from these studies are:

- A very low percentage (about 10\%) of migraine patients utilized triptans.

- When utilized, triptans were prescribed only once in a year in a large percentage (40-60\%) of patients.

- A minority of patients (5-10\%) utilize a large amount (40-45\%) of triptans, and some of these are classified as triptans abusers.

- A considerable percentage of triptans are prescribed in people aged over 65 .

- The low percentage of triptans users can be due to the low rate of diagnosis of migraine and the high utilization of over-the-counter drugs (OTC). Less than $50 \%$ of people suffering from migraine are not recognized by their general practitioner as having migraine and less than $30 \%$ of these have adequate management of migraine [29]. Possible causes of underdiagnosis and management by general practitioner are: poor time to spend with the patient, complexity of diagnostic criteria of IHS [26], variability of the clinical manifestations in migraine patients [30, 31], high utilization of OTC drugs [1], and high cost of triptans.

The high percentage of single prescriptions of triptans could indicate that many migraine patients had low frequency of attacks; in fact it was reported that only $20 \%$ patients had more than 14 migraine days per year [32]. Other studies reported an higher frequency: $75 \%$ of migraine patients have $0-3$ attacks/months and $25 \%$ more than one attack/week $[2,17]$. Another interpretation of the low percentage and frequency of triptans use is that many migraine patients cannot completely control migraine by triptans therapy because of lack of efficacy and/or side effects. Rahimtoola et al. [28] found that the main reasons for discontinuing treatment after only one prescription, was 
inefficacy and/or the occurrence of side effects. Maybe some patients tested a triptan but thereafter they do not require it again. This assumption was supported by the fact that although new triptan users are a large proportion of total users, the percentage of triptans users during the years has remained low. There are reports showing that an important subset of triptan users is dissatisfied with their usual care and about $80 \%$ would be willing to try another acute medication [33].

Acknowledgments The authors would like to thank Marno Institute (Castelnuovo Misericordia, Livorno, Italy) for their valuable collaboration in managing the data on triptans prescription.

\section{References}

1. MacGregor EA, Brandes J, Eikermann A (2003) Migraine prevalence and treatment patterns: the global migraine and zolmitriptan evaluation survey. Headache 43:19-26

2. Lipton RB, Diamond S, Reed M, Diamond ML, Stewart WF (2001) Migraine diagnosis and treatment: results from the American Migraine Study II. Headache 41:638-645

3. Ferrari MD, Roon KI, Lipton RB, Goadsby PJ (2001) Oral triptans (serotonin 5-HT1B/1D agonists) in acute migraine treatment: a meta-analysis of 53 trials. Lancet 358:1668-1675

4. Panconesi A, Pavone E, Banfi R (2006) Triptan utilization patterns: a study based on patients prescription records of an Italian health authority in Tuscany. J Headache Pain 7:266-267 (abstract)

5. Pavone E, Banfi R, Vaiani M, Panconesi A (2007) Patterns of triptans use: a study based on the records of a community pharmaceutical department. Cephalalgia 27:1000-1004

6. Panconesi A, Pavone E, Vaiani M, Banfi R, Cinaglia I (2007) Pattern of triptans use in the population: why the sub-utilization? Cephalalgia 27:741 (abstract)

7. Gaist D (1999) Use and overuse of sumatriptan. Pharmacoepidemiological studies based on prescription register and interview data. Cephalalgia 19:735-761

8. Etemad LR, Yang W, Globe D, Barlev A, Johnson KA (2005) Costs and utilization of triptan users who receive drug prophylaxis for migraine versus triptan users who do not receive drug prophylaxis. J Manag Care Pharm 11:137-144

9. Lohman JJHM, van der Kuy-de Ree MM (2005) Patterns of specific antimigraine drug use-a study based on the records of 18 community pharmacies. Cephalalgia 25:214-218

10. Perearnau P, Vuillemet F, Schick J, Weill G (2006) Patterns of prescription and usage of triptans in Alsace (France): misuse is frequent and avoidable. Rev Neurol 162:347-357

11. Dekker F, Wiendels NJ, van der Vliet C, de Valk V, Knuistingh A, Ferrari MD, Assendelft WJJ (2007) Triptan use and overuse in the Netherlands, a national pharmaco-database analysis. Cephalgia 27:683 (abstract)

12. Ifergane G, Wirguin I, Shvartzman P (2006) Triptans-Why once? Headache 46:1261-1263

13. Lugardon S, Roussel H, Sciortino V, Montastruc JL, LapeyreMestre M (2007) Triptan use and risk of cardiovascular events: a nested-case-control study from the French health system database. Eur J Clin Pharmacol 63:801-807

14. Sondergaard J, Foged A, Kragstrup J, Gaist D, Gram LF, Sindrup SH, Muckadell HUS, Larsen BO, Herborg H, Andersen M (2006) Intensive community pharmacy intervention had little impact on triptan consumption: a randomized controlled trial. Scand J Prim Health Care 24:16-21

15. Hoffman L, Mayzell G, Pedan A, Farrel M, Gilbert T (2003) Evaluation of a monthly coverage maximum (drug-specific quantity limit) on the 5-HT1 agonists (triptans) and dihydroergotamine nasal spray. J Manag Care Pharm 9:335-345

16. Lucas C, Auray J-P, Gaudin A-F, Dartigues J-F, Duru G, Henry P, Lanteri-Minet M, Pradalier A, Chazot G, El Hasnaoui A (2004) Use and misuse of triptans in France: data from the GRIM2000 population survey. Cephalalgia 24:197-205

17. Lucas C, Chaffaut C, Artaz M-A, Lanteri-Minet M (2005) FRAMIG 2000: medical and therapeutic management of migraine in France. Cephalalgia 25:267-279

18. Williams D, Cahill T, Dowson A, Fearon H, Lipscombe S, O'Sullivan E, Rees T, Strang C, Valori A, Watson D (2002) Usage of triptans among migraine patients: an audit in nine GP practices. Curr Med Res Opin 18:1-9

19. Ferrari A, Pasciullo G, Savino G, Cicero AFG, Ottani A, Bertolini A, Sternieri E (2004) Headache treatment before and after the consultation of a specialized centre: a pharmacoepidemiology study. Cephalalgia 24:356-362

20. Jelinski SE, Becker WJ, Christie SN, Giammarco R, Mackie GF, Gawel MJ, Eloff AG, Magnusson JE (2006) Clinical features and pharmacological treatment of migraine patients referred to headache specialists in Canada. Cephalalgia 26:578-588

21. Gaist D, Andersen M, Aarup AL, Hallas J, Gram LF (1997) Use of sumatriptan in Denmark in 1994-5: an epidemiological analysis of nationwide prescription data. Br J Clin Pharmacol 43:429433

22. Rahimtoola H, Buurma H, Tijssen CC, Leufkens HG, Egberts ACG (2003) Single use of sumatriptan: a patient interview study. Headache 43:109-116

23. Tepper S, Allen C, Sanders D, Greene A, Boccuzzi S (2003) Coprescription of triptans with potentially interacting medications: a cohort study involving 240,268 patients. Headache 43:44-48

24. Visser WH, de Vriend RH, Jaspers MW, Ferrari MD (1996) Sumatriptan in clinical practice: a 2-year review of 453 migraine patients. Neurology 47:46-51

25. Limmroth V, Katsarava Z, Fritsche G, Przywara S, Diener HC (2002) Features of medication overuse headache following overuse of different acute headache drugs. Neurology 59:10111014

26. Headache Classification Committee of the International Headache Society (2004) The international classification of headache disorders. Cephalagia 24(Suppl 1):1-160

27. Roussel H, Lo Re G, Honorat C, Alonso M, Sciortino V (2006) The use of triptan in ambulatory medicine in Midi-Pyrenees region: clinical and pharmacological contra-indications and drug abuse. Therapie 61:507-516

28. Rahimtoola H, Egberts ACG, Buurma H, Tijssen CC, Leufkens HG (2001) Patterns of ergotamine and sumatriptan use in the Netherlands from 1991 to 1997. Cephalalgia 21:596-603

29. De Diego EV, Lanteri-Minet M (2005) Recognition and management of migraine in primary care: influence of functional impact measured by the headache impact test (HIT). Cephalalgia 25:184-190

30. Nachit-Ouinekh F, Dartigues J-F, Chrysostome V, Henry P, Sourgen C, El Hasnaoui A (2005) Evolution of migraine after 10year follow-up. Headache 45:1280-1287

31. Woeber C, Woeber-Bingoel C, Schmidt K, Zingerle R, Hattinger N, Hartl T, Zahlbruckner L, Boettcher A, Hanslik K, Aydinkoc K, Geuder E, Wessely P (2005) Symptomatology, impact and treatment of 6,000 headache attacks and episodes: the pamina study. Cephalalgia 25:646 (abstract) 
32. Lygberg AC, Rasmussen BK, Jorgensen T, Jensen R (2005) Prognosis of migraine and tension-type headache: a populationbased follow-up study. Neurology 65:580-585
33. Bigal M, Rapoport A, Aurora S, Sheftell F, Tepper S, Dahlof C (2007) Satisfaction with current migraine therapy: experience from three centers in US and Sweden. Headache 47:475-479 